\title{
ЦИФРОВАЯ СИНЕРГЕТИКА ВЗАИМОДЕЙСТВИЯ ВНУТРИГОДОВОЙ АКТИВНОСТИ ЭКОНОМИЧЕСКОЙ ДЕЯТЕЛЬНОСТИ И ГОДОВОЙ ДИНАМИКИ ВАЛОВОГО ВНУТРЕННЕГО ПРОДУКТА
}

\author{
М.М. Новиков*
}

По результатам декомпозиции наблюдаемых уровней квартальных показателей валового внутреннего продукта определены статистически значимые составляющие его динамики: динамическая сезонной цикличности, тренд-циклическая и кратковременных колебаний. Предложена методология исследования влияния энергетики внутригодовой активности экономической деятельности на динамику годовых показателей валового внутреннего продукта.

Аналитика исследования апробирована на фактических материалах годовых и квартальных показателей валового внутреннего продукта Республики Беларусь за период 2009-2017 гг.

Ключевые слова: приведенная шкала фактора времени, валовой внутренний продукт, квартальная и годовая периодичность, кинетическая энергетика, внутригодовая активность, годовая динамика.

JEL-классификация: C22, C43, C82, E32, H12.

DOI: $10.46782 / 1818-4510-2020-2-118-131$

Материал поступил 12.02.2020 2.

Экономическая динамика Беларуси наполнена потоками движения доходов и расходов, движущимися в пространстве и времени в разных направлениях, с различными параметрами скорости, ускорения, периодичностью и изменениями во времени. Траектории этих потоков пересекаются во множестве точек экономического пространства и времени. Внешне это многообразие движений представляется хаотичным вследствие того, что поведение явлений и процессов экономического пространства и времени определяется множеством причинно-следственных связей. По отношению к изучаемому явлению одни из них выступают в качестве главных, решающих, а другие играют вспомогательную роль. Первые действуют в соответствии с волей и желанием людей или под воздействием сил природы. Влияние других - разнонаправленно. Они могут способствовать или препятствовать развитию явления. Взаимное переплетение множества причинно-следственных связей формирует картину мас- сового процесса. В ряде случаев значения случайных факторов с противоположными знаками погашаются. В результате проявляется действие основополагающих факторов, под влиянием которых формируется статистическая закономерность. Под воздействием главных, решающих факторов неравновесные процессы приводятся в состояние равновесия. С приливом вновь привходящих энергообразующих информационных потоков в экономическую среду создается и поддерживается новая стадия ее неравновесности и т. д.

Современный мир нестабилен. Постньютоновская гносеология его познания концентрирует внимание на познавательных процессах взаимосвязи структурных элементов микроуровня, а также на их взаимодействии с макроуровнем. Идея нестабильности потеснила детерминизм и в поле зрения естествознания включила человеческую деятельность. Подтверждением острой потребности использования «зарубежного опыта взаимодействия микро- и макроуров-

* Новиков Михаил Михайлович (mm_novikov@rambler.ru), доктор экономических наук, профессор, Белорусский государственный экономический университет (г. Минск, Беларусь). 
ней управления экономикой в целях повышения эффективности инновационной деятельности» может послужить работа (Капорцева, 2018).

Система национальных счетов (СНC) информационно-методологический стандарт рыночной экономики, который пока не полностью внедрен в статистическую практику Республики Беларусь. В нем содержится ряд специфических требований и правил сцепления и увязки годовых и квартальных показателей, которые рекомендуется соблюдать в аналитических исследованиях их динамики ${ }^{1}$.

В формировании равновесных процессов социально-экономического развития проявляется самоорганизующая сила общества. В этом состоит и проявляется кинетическая энергетика экономической динамики как прообраз синергетики, «являющейся относительно новым научным направлением междисциплинарных исследований в рамках нелинейной онтологии, которое заключается в выявлении закономерностей протекания процессов самоорганизации в сложных открытых системах» (Румянцева, 2014).

Парадигма синергетики приобретает самое актуальное значение в поиске нелинейных решений по устранению кризисных проявлений в экономике.

В своеобразном формате синергетической парадигмы раскрывается видение преобразований поведенческой экономики Беларуси и ее раскодирование в (Рудый, 2017. C. 320-327).

Энергетика взаимодействия динамики показателей различной периодичности, по авторскому убеждению, встраивается в гносеологию бифуркационных процессов макродинамики так, как они специфицированы в источнике (Пригожин, Стенгерс, 1986). Бифуркация - поворотная точка перехода массового процесса от хаоса к порядку. В терминологии экономической динамики она наполняется смысловым содержанием кризисных проявлений в развитии и поиска вариантов по их преодолению. В этом качестве она выступает в форме поворот-

${ }^{1}$ Система национальных счетов 2008. 2012. Нью-Йорк. URL: https://unstats.un.org/unsd/publication/SeriesF/ SeriesF 2Rev5r.pdf ной точки экономической динамики по определению представителей ряда международных и национальных организаций о сущности, фазах, переломных точках, показателях кризиса и подъема (Зенькова, Новиков, 2019. С. 17-40; Малаховская, Пекарский, 2012; Bernanke, Woodford, 2005; Hansen, Sardgent, 2008; Быков, 2014)².

Концепции цифровых технологий могут быть по-разному определены и охарактеризованы их цифровыми характеристиками. Так, например, в работе (Ельсуков, Кузьмич, 2018. С. 2017) цифровизация управления инновациями представлена такими характеристиками, как: цифровизация цепочек производства валовой добавленной стоимости; цифровизация наращивания валовой добавленной стоимости за счет оказания услуг в дополнение к производству товаров; введение в практику цифрового бизнес-моделирования как формы активизации взаимодействия с клиентами. Д.В. Евтянова и М.В. Тиранова (2017) цифровую экономику эффективной экономической политики с учетом экологической составляющей представляют в форме автоматизированного управления хозяйством на основе передовых информационных технологий.

В настоящем исследовании решается задача цифровой спецификации составляющих внутригодовой активности экономической деятельности и их взаимодействия с годовой динамикой валового внутреннего продукта. Цифровизация искомых составляющих при этом представлена цифровыми характеристиками скорости, кратности пробега годовой динамики по внутригодовым отрезкам фактора времени, а также энергетики внутригодовой активности по таким составляющим годовой динамики как: динамическая составляющая сезонной цикличности, тренд-циклическая составляющая и иррегулярная составляющая краткосрочных колебаний.

Статистическая спецификация энергетики внутригодовой активности вскрывает временные закономерности формирования накопительных эффектов взаимодействия динамики показателей различной пе-

\footnotetext{
${ }^{2}$ Хакен Г. Самоорганизующееся общество. URL: https:/ /booksee.org/book/992490
} 
риодичности разработки как формы аналитического предвидения ожидаемой годовой динамики в зависимости от внутригодовой активности ретроспективной экономической деятельности. Такая постановка задачи приобретает особенно актуальное значение в контексте визуализации информационных потоков макроэкономического уровня и вхождения страны в цифровую экономику.

\section{Аналитическая спещификащия взаимодействия годовых и квартальных показателей экономической динамики}

Кинетическая энергетика (синергетика) экономической динамики рассматривается в контексте установления закономерностей упорядоченного взаимодействия динамики:

потоков годовых и квартальных показателей сезонной, тренд-циклической и иррегулярной составляющих движения доходов в макроэкономической системе;

динамического моделирования их равновесного взаимодействия в категориях оценки параметров: мультипликации, акселерации, а также разработки и решения характеристического уравнения, позволяющих проводить диагностику стабилизации их колебательной динамики. Настоящая статья вмещает только первую часть сформулированной проблематики.

Квартальные и годовые показатели стартуют и завершают хозяйственный год в разные моменты времени. Для показателей I квартала он завершается к 1 апреля. Показатели II квартала являются предвестниками ожидаемых результатов завершения годовой деятельности по состоянию на 1 июля. Предсказательная сила данных за III квартал формируется к началу октября. Результаты годовой экономической деятельности за IV квартал в высокой степени предсказуемы по информационным данным девятимесячной ретроспективы. Такая степень предсказательной уверенности относится к формированию ожидаемых оценок по текущим, цепным показателям динамики. Кинетическая энергетика базисных показателей экономической динамики будет выше текущей по причине более обширной базы исходных данных. Тем самым квартальные показатели тренд-циклической составляющей движения доходов в макроэкономической системе наполняются экономическим содержанием опережающих параметров - предвестников ожидаемой динамики их годовых показателей. В этом контексте аналитическое моделирование энергетических эффектов их взаимодействия приобретает актуальное значение.

Энергетика квартальных компонентов тренд-циклической составляющей передается годовым показателям посредством скоростного режима их движения в информационной среде измерения их годовых приростов в системе непрерывной шкалы фактора времени. В соответствии с уравнением (1) приращение годового объема показателя $X$ равно сумме годовых приращений его квартальных компонентов. Применительно к режиму выхода на цепной годовой прирост некоторого показателя $Y$, обусловленного динамикой его квартальных компонентов, будем иметь:

$$
\begin{aligned}
& Y_{t}-Y_{t-1}=\left(X_{1, t}-X_{1, t-1}\right)+\left(X_{2, t}-X_{2, t-1}\right)+ \\
&+\left(X_{3, t}-X_{3, t-1}\right)+\left(X_{4, t}-X_{4, t-1}\right), \\
& \text { или } \quad \Delta Y_{t}=\sum_{i=1}\left(X_{i, t}-X_{i, t-1}\right),
\end{aligned}
$$

где $i=1,2,3,4$ - порядковые номера кварталов;

$t$ - порядковый номер года.

В скобках аналитического тождества (1) представлены приросты квартальных показателей с годовым шагом фактора времени. Будучи по своей форме базисными показателями абсолютных приростов, они могут быть развернуты в аддитивную форму соответствующих цепных приростовых значений, которые с приведением подобных членов преобразуются в аналитическое тождество

$$
\begin{aligned}
& \sum_{t} \Delta X_{i, t}=1 \cdot\left(X_{2, t-1}-X_{1, t-1}\right)+2 \cdot\left(X_{3, t-1}-X_{2, t-1}\right)+ \\
& +3 \cdot\left(X_{4, t-1}-X_{3, t-1}\right)+4 \cdot\left(X_{1, t}-X_{4, t-1}\right)+ \\
& +3 \cdot\left(X_{2, t}-X_{1, t}\right)+2 \cdot\left(X_{3, t}-X_{2, t}\right)+1 \cdot\left(X_{4, t}-X_{3, t}\right) \\
& \quad \text { В тождестве (3) представлено упоря- }
\end{aligned}
$$
доченное множество цепных приростовых оценок квартальных показателей, взвешенное по коэффициентам кратности пробега 
годовой динамики. Его совокупный эффект (годовая энергетика) эквивалентно соответствует вкладу внутригодовых аналитических компонентов (внутригодовой активности) скоростного режима движения квартальных составляющих в годовой прирост объема исследуемого явления. В соотношении с базисным уровнем анализируемого показателя годовая энергетика экономической динамики приобретает относительные оценки своего выражения. По результатам вынесения за скобки вычитаемого компонента уравнение (3) преобразуется в (4):

$$
\begin{aligned}
& \sum_{i} \Delta X_{i, t}=1 \cdot\left(I_{X_{2 / 1, t-1}}-1\right) \cdot X_{1, t-1}+ \\
& +2 \cdot\left(I_{X_{3 / 2, t-1}}-1\right) \cdot X_{2, t-1}+3 \cdot\left(I_{X_{4 / 3, t-1}}-1\right) \cdot X_{3, t-1}+ \\
& +4 \cdot\left(I_{X_{1, t / 4, t-1}}-1\right) \cdot X_{4, t-1}+3 \cdot\left(I_{X_{2 / 1, t}}-1\right) \cdot X_{1, t}+ \\
& +2 \cdot\left(I_{X_{3 / 2, t}}-1\right) \cdot X_{2, t}+1 \cdot\left(I_{X_{4 / 3, t}}-1\right) \cdot X_{3, t},
\end{aligned}
$$

аддитивные составляющие которого представлены произведениями цепных темпов прироста на уровень показателя за предшествующий квартал, взвешенные по коэффициентам кратности пробега годовой динамики.

Уравнение (3) является аналитической формой спецификации синергетики взаимодействия динамики квартальных и годовых показателей в условиях их аддитивной взаимосвязи, в то время как уравнением (4) описывается аддитивно-мультипликативное их взаимодействие. Квартальные показатели, будучи сложными экономическими характеристиками, содержат в себе сезонную и тренд-циклическую составляющие. Сезонная составляющая формируется под воздействием природных и организационно-экономических факторов. В условиях климатических изменений сезонная составляющая приобретает динамическую форму своего проявления и действия. Динамическая составляющая сезонной цикличности является факторным компонентом экономической динамики годового уровня ${ }^{3}$.

Уравнениями (3) и (4) обеспечивается однозначная оценка вклада в годовую динамику внутригодовой активности и ее факторных составляющих по всем времен-

3 Новиков М.М. 2019. Изменения в сезонной цикличности ВВП: поиск причинно-следственной обусловленности. Бухгалтерский учет и анализ. № 10. С. 3-15. ным отрезкам, начиная со II квартала базисного года и заканчивая IV кварталом отчетного года4 ${ }^{4}$ При наличии исходных данных месячной периодичности подобные оценки могут быть выполнены, начиная со второго месяца года, принятого за базу сравнения годовой динамики.

\section{Инновационная методология сезонной декомпозиции квартальных показателей валового внутреннего продукта}

В табл. 1 представлена декомпозиция наблюдаемых уровней квартальных показателей валового внутреннего продукта Республики Беларусь с вычленением кратковременных колебаний (графа 4), трендциклической составляющей (графа 5) и динамической составляющей сезонной цикличности (графа 6) за 2009-2017 гг. Составляющая кратковременных колебаний получена по методу фильтрации наблюдаемых уровней квартальных показателей ВВП, в процессе которой произведено отсеивание колебательных процессов 4-го и более высоких порядков.

Методика фильтрации включает в себя следующую последовательность аналитических алгоритмов. На первой стадии выполняется аналитическое выравнивание квартальных уровней валового внутреннего продукта по системе наилучших функций с применением приведенной шкалы фактора времени при годовом шаге признака времени. Применительно к условиям моделирования динамики показателей квартальной периодичности в приведенной шкале фактора времени кодировка временного признака в кварталах совмещается (приводится) к годовым единицам измерения масштаба времени. Тем самым в приведенной шкале фактора времени признак времени представлен как целыми, так и дробными числовыми обозначениями в годах, как это показано в графе 2 табл. 1, с временнљм шагом 0,25 года. При этом подбор наилучшей функции осуществляется по критерию минимизации ошибки аппроксимации или максимизации коэффициента детермина-

${ }^{4}$ Новиков М.М. 2017. Аддитивно-мультипликативное индексное моделирование экономической динамики с учетом криволинейного взаимодействия показателей. Бухгалтерский учет и анализ. № 2. С. 52-53. 
Сезонная декомпозиция квартальных показателей валового внутреннего продукта Республики Беларусь в приведенной шкале фактора времени за 2009-2017 гг., в среднегодовых ценах 2009 г., млрд руб.

\begin{tabular}{|c|c|c|c|c|c|c|}
\hline \multirow[b]{2}{*}{$\begin{array}{c}\text { Год, } \\
\text { квартал }\end{array}$} & \multirow[b]{2}{*}{$\begin{array}{c}\text { Приве- } \\
\text { денная } \\
\text { шкала } \\
\text { фактора } \\
\text { времени }\end{array}$} & \multirow[b]{2}{*}{$\begin{array}{c}\text { Наблюдаемые } \\
\text { уровни } \\
\text { квартальных } \\
\text { показателей, } \\
Y(t)\end{array}$} & \multirow[b]{2}{*}{$\begin{array}{c}\text { Составляю- } \\
\text { щая кратко- } \\
\text { срочных } \\
\text { колебаний, } \\
(\text { гр. } 3 \text { - гр. } 5)\end{array}$} & \multirow[b]{2}{*}{$\begin{array}{c}\text { Квартальные } \\
\text { показатели } \\
\text { в оценке по } \\
\text { системе } \\
\text { наилучших } \\
\text { функций, } \\
\hat{Y}(t)\end{array}$} & \multicolumn{2}{|c|}{ В том числе } \\
\hline & & & & & $\begin{array}{c}\text { Тренд- } \\
\text { циклическая } \\
\text { составляющая, } \\
\hat{Y}(t)\end{array}$ & $\begin{array}{c}\text { Динамическая } \\
\text { составляющая } \\
\text { сезонной } \\
\text { цикличности, } \\
u(t)(\text { гр. } 5 \text { - гр. 6) }\end{array}$ \\
\hline 1 & 2 & 3 & 4 & 5 & 6 & 7 \\
\hline 2009 г. І кв. & 0,25 & 30489,40 & 402,97 & 30086,43 & 32352,44 & $-2266,01$ \\
\hline II кв. & 0,50 & 33302,60 & 524,55 & 32778,05 & 33446,07 & $-668,02$ \\
\hline III кв. & 0,75 & 39020,90 & $-418,7$ & 39439,60 & 34440,11 & 4999,49 \\
\hline IV кв. & 1,00 & 34629,30 & $-1401,98$ & 36031,28 & 35339,21 & 692,07 \\
\hline 2010 г. I кВ. & 1,25 & 31785,80 & $-852,61$ & 32638,41 & 36148,01 & $-3509,60$ \\
\hline II кв. & 1,50 & 36373,40 & $-1062,06$ & 37435,46 & 36871,16 & 564,30 \\
\hline III кв. & 1,75 & 41761,10 & 630,09 & 41131,01 & 37513,31 & 3617,70 \\
\hline IV кв. & 2,00 & 38161,00 & 1217,98 & 36943,02 & 38079,10 & $-1136,08$ \\
\hline 2011 г. I кв. & 2,25 & $35 \quad 139,70$ & 451,18 & 34688,52 & 38573,16 & $-3884,64$ \\
\hline II кв. & 2,50 & 40442,00 & 258,27 & $40 \quad 183,73$ & 39000,15 & 1183,58 \\
\hline III КВ. & 2,75 & 42451,30 & 2,91 & 42448,39 & 39364,72 & 3083,67 \\
\hline IV кв. & 3,00 & 38257,50 & 402,74 & 37854,76 & 39671,49 & $-1816,73$ \\
\hline 2011 г. I кВ. & 2,25 & 35139,70 & 451,18 & 34688,52 & 38573,16 & $-3884,64$ \\
\hline II кв. & 2,50 & 40442,00 & 258,27 & 40183,73 & 39000,15 & 1183,58 \\
\hline III кв. & 2,75 & 42451,30 & 2,91 & 42448,39 & 39364,72 & 3083,67 \\
\hline IV кв. & 3,00 & 38257,50 & 402,74 & 37854,76 & 39671,49 & $-1816,73$ \\
\hline 2012 г. I кв. & 3,25 & 36304,70 & 67,92 & 36236,78 & 39925,13 & $-3688,35$ \\
\hline II кв. & 3,50 & 41514,80 & 80,92 & 41433,88 & 40130,27 & 1303,61 \\
\hline III кв. & 3,75 & 43115,60 & $-276,16$ & 43391,76 & 40291,56 & 3100,20 \\
\hline IV кв. & 4,00 & 38061,40 & $-705,1$ & 38766,50 & 40413,64 & $-1647,14$ \\
\hline 2013 г. І кв. & 4,25 & 36667,70 & $-615,48$ & 37283,18 & 40501,16 & $-3217,98$ \\
\hline II кв. & 4,50 & 41929,90 & 332,99 & 41596,91 & 40558,76 & 1038,15 \\
\hline III кв. & 4,75 & 43546,80 & $-414,3$ & 43961,10 & 40591,08 & 3370,02 \\
\hline IV кв. & 5,00 & 38442,00 & $-1236,25$ & 39678,25 & 40602,77 & $-924,52$ \\
\hline 2014 г. І кв. & 5,25 & 38753,59 & 925,88 & 37827,71 & 40598,48 & $-2770,77$ \\
\hline II кв. & 5,50 & 41574,74 & 490,9 & 41083,84 & 40582,85 & 500,99 \\
\hline III КВ. & 5,75 & 45519,17 & 1362,74 & 44156,43 & 40560,52 & 3595,91 \\
\hline IV кв. & 6,00 & 43757,36 & 3167,38 & 40589,98 & 40536,13 & 53,85 \\
\hline 2015 г. I кВ. & 6,25 & 37960,35 & 89,96 & 37870,39 & 40514,34 & $-2643,95$ \\
\hline II кв. & 6,50 & 39767,8 & $-537,87$ & 40305,67 & 40499,79 & $-194,12$ \\
\hline III кв. & 6,75 & 43584,99 & $-392,74$ & 43977,73 & 40497,11 & 3480,62 \\
\hline IV кв. & 7,00 & 41796,59 & 294,86 & 41501,73 & 40510,96 & 990,77 \\
\hline 2016 г. I кв. & 7,25 & 36613,34 & $-797,87$ & 37411,21 & 40545,98 & $-3134,77$ \\
\hline II кВ. & 7,50 & 39228,37 & $-445,03$ & 39673,40 & 40606,81 & $-933,41$ \\
\hline III кв. & 7,75 & 42081,67 & $-1443,34$ & 43525,01 & 40698,10 & 2826,91 \\
\hline IV кв. & 8,00 & 41065,46 & $-1348,01$ & 42413,47 & 40824,49 & 1588,98 \\
\hline 2017 г. І кВ. & 8,25 & 36778,15 & 327,99 & 36450,16 & 40990,62 & $-4540,46$ \\
\hline II кВ. & 8,50 & 39955,38 & 357,32 & 39598,06 & 41201,15 & $-1603,09$ \\
\hline III кв. & 8,75 & 43347,72 & 849,45 & 42498,27 & 41460,72 & 1037,55 \\
\hline IV кв. & 9,00 & 42933,49 & $-391,72$ & 43325,21 & 41773,96 & 1551,25 \\
\hline
\end{tabular}

Источник. Авторская разработка по данным: Национальные счета Республики Беларусь 2014: стат. сборник. 2014. Минск: Национальный статистический комитет Республики Беларусь. Комитет. С. 191; Национальные счета Республики Беларусь 2017: стат. сборник. 2017. Минск: Национальный статистический комитет Республики Беларусь. С. 22.

ции применительно к исходным данным по каждому кварталу в отдельности. В настоящем исследовании по заданному критерию наилучшими функциями оказались: однократно, применительно к данным IV квартала - линейная функция, а по данным других кварталов - полиномы 2-го и 3-го порядков. Названные аналитические 
функции с оценками статистической значимости их параметров по $t$-критерию Стьюдента. Статистически значимые временные тенденции специфицированы следующими аналитическими уравнениями. Наилучшей функцией в описании девятилетней временной тенденции ВВП за I квартал с годовым интервалом фактора времени оказался полином 2-го порядка. Его уравнение с оценками статистической значимости параметров на 5\%-м уровне:

$$
\begin{gathered}
Y(t)=29370,02+2928.37 t-250,93 t^{2}+u(t), \\
t-\text { критерий: } 44,849 \quad 8,146-6,141 \\
R=0,874 \quad F(1,7)=130,11 .
\end{gathered}
$$

Параметры уравнения (5) указывают на замедленный рост физического объема ВВП за І-й квартал исследуемого временного периода, а приведенные оценки значимости по $t$ - и $F$-критериям подтверждают статистическую надежность параметров и уравнения в целом. Ниже приводятся также уравнения годовых трендов квартальных показателей валового внутреннего продукта Республики Беларусь за II-IV кварталы, относящиеся к 2009-2017 гг. Они представлены различными формами их аналитической спецификации. Все они, однако, остаются статистическими значимыми на 5\%-м уровне. Так, статистическая значимость временной тенденции ВВП за II квартал нашла свое аналитическое воплощение в формате полиномиального тренда 3-го порядка:

$Y(t)=29604,99+6960,42 t-1262,82 t^{2}+68,50 t^{3}+u(t)$,

$t$-критерий: $29,4917,116-4,9003,700$

$$
R=0,981 \quad F(1,7)=174,85 \text {. }
$$

По данным за III квартал по критерию наилучшей аппроксимации признано уравнение полиномиального тренда 2-го порядка:

$$
\begin{gathered}
Y(t)=37925,60+2158,93 t-187,01 t^{2}+u(t), \\
t-\text { критерий: } 35,099 \quad 4,106-3,473 \\
R=0,886 \quad F(1,7)=25,533 .
\end{gathered}
$$

Аналитической особенностью временной тенденции валового внутреннего продукта за III квартал, подкрепленной оценками статистической значимости, является замедленный рост квартальных уровней.

Своеобразные особенности экономической динамики присущи квартальным показателям валового внутреннего продукта за IV квартал. В то время как в течение первых трех кварталов наблюдался замедленный рост квартальных показателей ВВП, в экономике четвертого квартала ежегодно формировалась линейная траектория экономической динамики. Это подтверждается статистически значимым линейным трендом квартальных показателей ВВП, он представлен уравнением

$$
\begin{aligned}
& Y(t)=35119,54+911,74 t+u(t), \\
& t \text {-критерий: } 30,780 \quad 4,438 \\
& R=859 \quad F(1,17)=19,696 .
\end{aligned}
$$

Наблюдаемые значения квартальных показателей, приведенные в графе 3 табл. 1, выравнены по уравнениям (5) - (8). Результаты их аналитической обработки помещены в графу 5 табл. 1. Посредством аналитического выравнивания наблюдаемых уровней квартальных показателей отфильтрована иррегулярная составляющая их экономической динамики. Иррегулярная составляющая абсорбирует случайный ее компонент. В ней могут также содержаться компоненты экономической динамики, детерминированные колебательными процессами высших порядков с присущими им оценками малой статистической значимости. Иррегулярная составля(6) ющая - сущностно не распознанная переменная экономической динамики. Количественные оценки иррегулярной составляющей воплощены в остаточном члене уравнений (5) - (8). По данным табл. 1, численные значения остаточного члена найдены посредством вычитания данных графы 5 из наблюдаемых уровней квартальных показателей, приведенных в графе 3.

В трендовых оценках квартальных показателей, полученных по системе наилучших функций (графа 5 табл. 1), содержатся значения тренд-циклической переменной и 
динамическая составляющая сезонной цикличности. Величина составляющей сезонной цикличности определена посредством вычитания из данных графы 5 тренд-циклической составляющей. Тренд-циклическая составляющая квартальных показателей определена в работе (Зенькова, Новиков, 2019. С. 69-85). Как переменная экономической динамики она воплощает в себе циклообразующие процессы регулярного свойства за исключением фактора сезонности. В качестве критерия подбора трендциклической составляющей квартальных показателей ВВП принята равнодействующая квартальных переменных в оценке по системе наилучших функций, как она представлена в графе 5 табл. 1. Она эквивалентна аналитической функции, воплощающей в себе состав колебательных компонентов экономической динамики, которые присущи показателю ВВП годовой периодичности. Применительно к данным Республики Беларусь на временном отрезке экономической динамики за 2001-2019 гг., названному критерию аналитической спецификации тренд-циклической составляющей квартальных показателей ВВП отвечает полином 3-й степени. Доказательным аргументом в пользу данной точки зрения выступает тот факт, что на 19-летнем временном интервале к наблюдаемым уровням годовых показателей ВВП статистически значимо аппроксимируется полином 3-й степени (Агабекова, 2017. С. 159). Исходя из этих соображений в настоящем исследовании поиск тренд-циклической составляющей выполнен посредством моделирования и оценки уровней полиномиального тренда 3-го порядка в аналитической разработке по значениям квартальных показателей, оцененных по системе наилучших функций. Аналитическая спецификация полиномиального тренда квартальных показателей ВВП 3-го порядка в разработке по данным графы 5 табл.1 представлена уравнением

$$
\begin{aligned}
& Y(t)=31154,59+5006,06 t-870,98 t^{2}+49,54 t^{3}+u(t), \\
& t \text {-критерий: } 15,734 \quad 2,738-1,910 \quad 1,527 \\
& R=0,674 \quad F(1,34)=28,368 .
\end{aligned}
$$

Уравнение полиномиального тренда (9) статистически значимо по F-критерию. Уравнение подразделяет совокупную вариацию квартальных показателей (за исключением случайной компоненты) на две составляющие. Они представлены относительными показателями доли тренд-циклической компоненты и доли динамической сезонной составляющей. При коэффициенте корреляции $R$ $=0,674$ множественный коэффициент детерминации составил $45,4 \%$. Это означает, что совокупные колебательные процессы годовой динамики ВВП на 45,4\% обусловлены колебательными свойствами длительного характера, в то время как на долю сезонной цикличности приходится $64,6 \%$. В составе полиномиального тренда, как он представлен уравнением (9), динамическая составляющая сезонной цикличности детерминирована его остаточным членом $u(t)$. Руководствуясь этим обстоятельством, динамическая составляющая сезонной цикличности, будучи остаточным членом тренд-циклической составляющей, определена разностью данных граф 5 и 6 табл. 1.

Как свидетельствуют данные табл. 1, наблюдаемые уровни квартальных показателей ВВП, представленные данными графы 3, аддитивно детерминированы динамической составляющей сезонной цикличности (графа 7), тренд-циклической составляющей (графа 6) и составляющей кратковременных колебаний экономической динамики (графа 4). Аналитическое тождество (3) - формализованная спецификация взаимодействия динамики показателей ВВП и его составляющих годовой и квартальной периодичности. Поименованные выше составляющие экономической динамики квартальных показателей ВВП в разработке по исходным данным граф 4, 6 и 7 табл. 1 исследованы на устойчивость их скоростных характеристик.

\section{Оценка әнергетики внутригодовой активности и ее взаимодействия с годовой динамикой ВВП}

Вышеназванные составляющие экономической динамики получены по результатам статистически значимых траекторий квартальных показателей ВВП, оцененных по системе наилучших функций, как они представлены уравнениями (5) - (8). Аналитиче- 
ским тождеством (3) описывается взаимодействие динамики показателей ВВП и его составляющих годовой и квартальной периодичности посредством системы цепных приростовых значений составляющих экономической динамики. В этой связи поставлена также задача дать оценку статистической значимости скоростных характеристик составляющих динамики квартальных показателей ВВП в оценке по сравнению с предыдущим кварталом. Изменения в составе трех вычлененных составляющих динамики ВВП приведены в табл. 2. Они представлены характеристиками векторных сдвигов в составляющих экономической динамики каждого из кварталов по сравнению с предыдущим кварталом.

Описание скоростного режима изменений квартальных компонентов динамической сезонной составляющей представлено уравнениями полиномиальных трендов, воспроизведенных ниже. Так, изменения в составе квартального компонента сезонной составляющей за II и III кварталы по сравнению с I и II кварталами соответственно описаны уравнениями полиномов 3-го порядка (10) и (11):

$\hat{Y}(t)=-2770,51+5451,81 t-1151,80 t^{2}+68,50 t^{3}$, $t$ - критерий : -305 $449733010-68409461652$

$$
R=1,000 \quad F(1,7)=9999 \mathrm{E} 8 .
$$

Уравнение изменений в составе квартального компонента сезонной составляющей за III квартал по сравнению со II кварталом:
$\hat{Y}(t)=10192,33-5598,66 t+1151,01 t^{2}-69,09 t^{3}$,

$t$ - критерий : 128,613 - 86,156 78,243 - 71,171

$$
R=9997 \quad F(1,7)=11769 .
$$

Аналитическая спецификация сдвигов по векторным компонентам IV и I кварталов представлена уравнениями полиномов 2-го порядка в формате уравнений (12) и (13).

Уравнение изменений в составе квартального компонента сезонной составляющей за IV квартал по сравнению с III кварталом:

$\hat{Y}(t)=-3561,36-893,34 t+149,10 t^{2}$,

$t$-критерий : $-80,729-44,103 \quad 75,473$

$$
R=99987 \quad F(1,7)=27446 .
$$

Уравнение изменений в составе квартального компонента сезонной составляющей за I квартал по сравнению с IV кварталом предыдущего года:

$$
\begin{gathered}
\hat{Y}(t)=-6230,95+2317,36 t-288,08 t^{2}, \\
t-\text { критерий : }-835629609562-698639 \\
R=1,000 \quad F(1,6)=7192 \mathrm{E} 8 .
\end{gathered}
$$

Оценка параметров уравнений (10) (13) выполнена по исходным данным граф 2-5 табл. 2. Все параметры уравнений (10) (13) статистически значимы на 5\%-м уровне. Статистически значимые сдвиги параметров скоростного режима с годовым шагом фактора времени с оценками тесноты связи, приближающимися к единице, присущи также векторным компонентам тренд-

\begin{tabular}{|c|c|c|c|c|c|c|c|c|c|c|c|c|}
\hline \multirow{3}{*}{ Год } & \multicolumn{4}{|c|}{$\begin{array}{c}\text { Сдвиги в динамической сезонной } \\
\text { составляющей }\end{array}$} & \multicolumn{4}{|c|}{ Сдвиги в тренд-циклической составляющей } & \multicolumn{4}{|c|}{$\begin{array}{c}\text { Изменения в составляющей краткосрочных } \\
\text { колебаний }\end{array}$} \\
\hline & вектор I & вектор II & вектор III & вектор IV & вектор I & вектор II & вектор III & вектор IV & вектор I & вектор II & вектор III & вектор IV \\
\hline & квартала & квартала & квартала & квартала & квартала & квартала & квартала & квартала & квартала & квартала & квартала & квартала \\
\hline 1 & 2 & 3 & 4 & 5 & 6 & 7 & 8 & 9 & 10 & 11 & 12 & 13 \\
\hline 2009 & - & 1597,99 & 5667,51 & $-4307,42$ & - & 1093,63 & 994,04 & 899,1 & - & 121,58 & $-943,25$ & $-983,28$ \\
\hline 2010 & $-4201,67$ & 4073,90 & 3053,40 & $-4753,78$ & 808,8 & 723,15 & 642,15 & 565,79 & 549,37 & $-209,45$ & 1692,15 & 587,89 \\
\hline 2011 & $-2748,56$ & 5068,22 & 1900,09 & $-4900,40$ & 494,06 & 426,99 & 364,57 & 306,77 & $-766,8$ & $-192,91$ & $-255,36$ & 399,83 \\
\hline 2012 & $-1871,62$ & 4991,96 & 1796,59 & $-4747,34$ & 253,64 & 205,14 & 161,29 & 122,08 & $-334,82$ & 13,00 & $-357,08$ & $-428,94$ \\
\hline 2013 & $-1570,84$ & 4256,13 & 2331,87 & $-4294,54$ & 87,52 & 57,6 & 32,32 & 11,69 & 89,62 & 948,47 & $-747,29$ & $-821,95$ \\
\hline 2014 & $-1846,25$ & 3271,76 & 3094,92 & $-3542,06$ & $-4,29$ & $-15,63$ & $-22,33$ & $-24,39$ & 2162,13 & $-434,98$ & 871,84 & 1804,64 \\
\hline 2015 & $-2697,80$ & 2449,83 & 3674,74 & $-2489,85$ & $-21,79$ & $-14,55$ & $-2,68$ & 13,85 & $-3077,42$ & $-627,83$ & 145,13 & 687,6 \\
\hline 2016 & $-4125,54$ & 2201,36 & 3760,32 & $-1237,93$ & 35,02 & 60,83 & 91,29 & 126,39 & $-1092,73$ & 352,84 & $-998,31$ & 95,33 \\
\hline 2017 & $-6129,44$ & 2937,37 & 2640,64 & 513,70 & 166,13 & 210,53 & 259,57 & 313,24 & 1676 & 29,33 & 492,13 & $-1241,17$ \\
\hline
\end{tabular}

Таблица 2

Изменения в составляющих динамической сезонной цикличности, тренд-циклической и кратковременных колебаний валового внутреннего продукта Республики Беларусь по вектору $k$-го квартала по сравнению с предыдущим кварталом за 2009-2017 гг. в среднегодовых ценах 2009 г., млрд руб.

Источник. Авторская разработка по данным табл. 1., графы 4, 6, 7. 
циклической составляющей квартальных показателей ВВП, показанных в графах 69 табл. 2. Наличие статистически значимых временных изменений в динамике векторных компонентов сезонной составляющей, а также тренд-циклической составляющей квартальных показателей ВВП является характерным признаком того факта, что они значимо определяют и его годовую динамику.

Годовые изменения в векторных компонентах составляющей кратковременных колебаний квартальных показателей (данные граф 10-13 табл. 2) присутствуют, однако они относятся к статистически не значимым. Вследствие этого ожидаемое их участие в формировании годовой динамики ВВП будет проявляться в форме малых циклических колебаний.

С помощью последовательности цепных приращений квартальных показателей, а равным образом и составляющих их годовой динамики, взвешенных по коэффициентам кратности пробега экономической деятельности, формируется внутригодовая активность составляющих экономической деятельности. В формализованном представлении эта аналитическая закономерность специфицирована аналитическим тождеством (3), а в цифровом освещении также данными табл. 3. В графе 2 табл. 3 представлены наблюдаемые уровни квартальных показателей валового внутреннего продукта за два смежных года. В графах 3-5 помещены абсолютные изменения (приросты) по трем составляющим экономической деятельности: иррегулярной составляющей, тренд-циклической составляющей и динамической составляющей сезонной цикличности. Их суммой по строке за II квартал 2016 г. в точности объясняется прирост квартального уровня ВВП за II квартал по сравнению с I кварталом:

$352,84+60,83+2201,36=39228,37-$ $36613,34=2615,03$ млрд руб.

В графе 6 табл. 3 приведены коэффициенты кратности пробега годовой динамики. Применительно к данным по строке за II квартал 2016 г. кратность пробега годовой динамики представлена единичным значением. Это означает, что квартальный показатель II квартала 2016 г. в оценке ди- намики объема ВВП за 2017 г. по сравнению с 2016 г. принимает однократное участие. Как обнаруживаем далее по данным графы 6, III квартал в оценке годовой динамики в представлении за 2017 г. по отношению к 2016 г. принимает двукратное участие, IV квартал - трехкратное, а I квартал 2017 г. по сравнению с IV кварталом 2016 г. - четырехкратное участие и т. д. Произведение абсолютных изменений составляющих экономической динамики по данным граф 3-5 на соответствующий коэффициент кратности пробега годовой динамики (графа 6) составляет энергетику внутригодовой активности как фактор годовой динамики исследуемого показателя. Отношение энергетики внутригодовой активности по заданному кварталу к базисному объему ВВП - относительный вклад энергетики внутригодовой активности в годовую динамику валового внутреннего продукта. В цифровом освещении по трем составляющим энергетики внутригодовой активности он проиллюстрирован в графах 8, 10 и 12 табл. 3. Накопительная кинетика вклада внутригодовой активности экономической деятельности в годовую динамику валового внутреннего продукта за 2017 г. по сравнению с 2016 г. показана в итоговой строке табл. 3.

В графе 2 табл. 3 приведены наблюдаемые уровни квартальных показателей ВВП за два смежных года. Нетрудно убедиться, что прирост ВВП за 2017 г. по сравнению с 2016 г. составил 4025,9 млрд руб. так как его объемы за 2017 г. и 2016 г. соответственно равны сумме его квартальных уровней:

Убеждаемся также, что алгебраическая сумма энергетики внутригодовой активности составляющих экономической деятельности по данным граф 7, 9 и 11 итоговой строки таблицы 3 в точности сбалансирована с данной оценкой.

Годовая динамика физического объема ВВП при этом составляет 102,532\% (163 014,74 / 158 988,84 · 100). Компоненты кинетической энергетики внутригодовой активности по иррегулярной составляющей (5177,29 млрд руб.) тренд-циклической составляющей (2751,07 млрд руб.) и динамической составляющей сезонной циклич- 


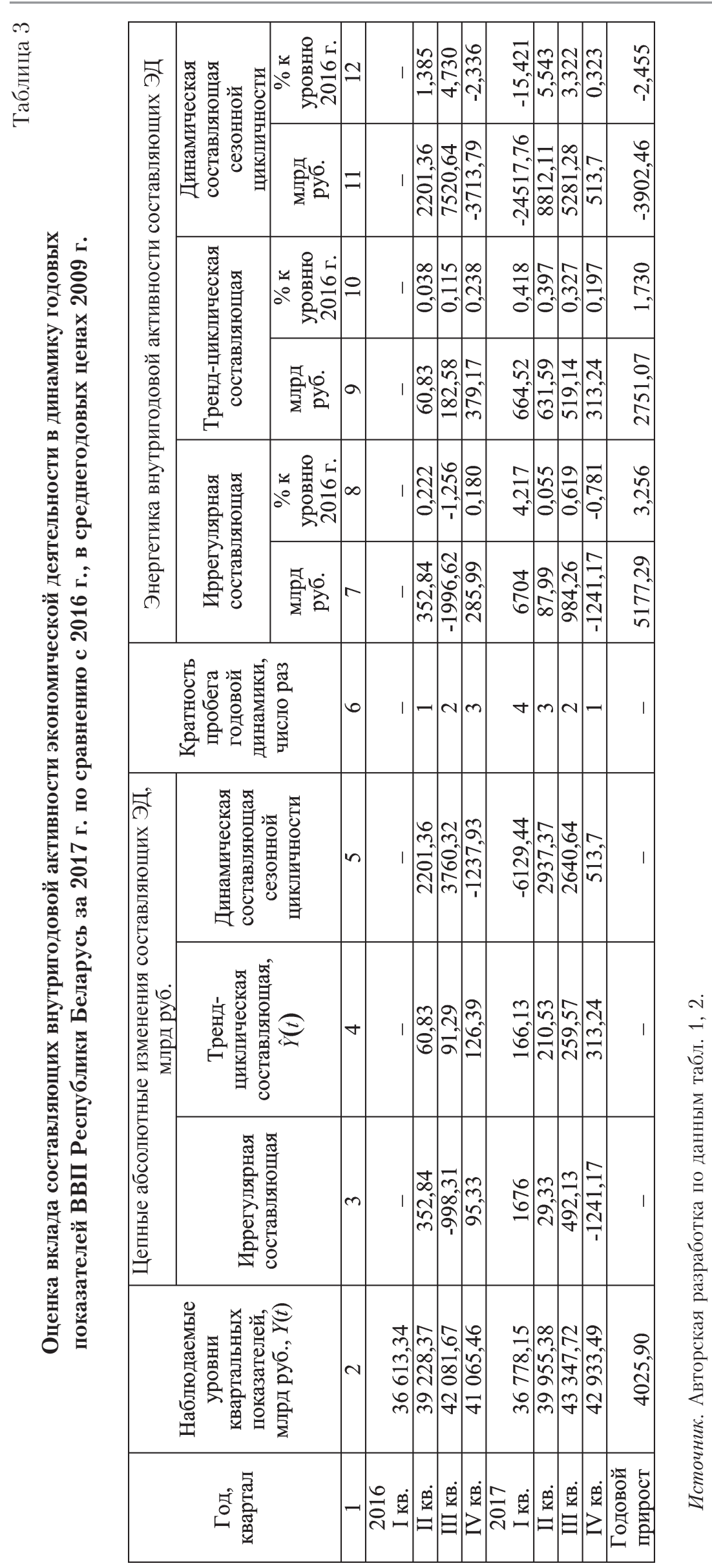


ности (-3902,46 млрд руб.), взятые по отношению к объему ВВП 2016 г., равному 158 988,8 млрд руб., равны итоговым оценкам вклада внутригодовой активности по каждой из составляющих экономической динамики в годовую динамику ВВП. В табл. 3 они приведены в графах 8, 10 и 12 по итоговой строке и аддитивно сбалансированы с годовым показателем динамики валового внутреннего продукта, так что

$3,256+1,730-2,455=2,531 \%$.

При этом итоговые показатели вклада структурно сбалансированы с соответствующими квартальными оценками аддитивной формой взаимодействия. Обращает на себя внимание участие в годовой динамике ВВП внутригодовой активности по динамической составляющей сезонной цикличности. Итоговая энергетика ее внутригодовой активности представлена негативной оценкой в размере $-2,455$ п. п. при -15,421 процентном вкладе по I кварталу 2017 г. В процессе идентификации сдвигов в сезонной цикличности выявлены следующие отличительные особенности. Сдвиги в сезонной цикличности по четвертому и первому кварталам преимущественно обусловлены организационно-экономическими факторами, а по II и III кварталам природно-климатическими изменениями. Характерной особенностью временного периода, начиная с 2012 г., явилось непрерывное наращивание квартальных объемов ВВП за IV квартал по сравнению с III кварталом, что следует интерпретировать как организационное следствие наверстывания упущений предыдущих кварталов посредством ускоренной мобилизации недоиспользованных материальных и финансовых ресурсов. Посредством повышения организационно-экономической активности экономической деятельности в IV квартале автоматически наращивается исходная база сравнения для I квартала следующего года. В этих условиях, даже при сохранении традиционного уровня внутригодовой активности, цепные оценочные характеристики скоростного режима экономической динамики понижаются. Таким образом, наверстанные результаты экономических упущений в IV квартале базисного года в терминологии динамической сезонной циклич- ности исчезают в I квартале отчетного года и количественно проявляются в форме понижения уровня внутриквартальной квартальной активности. В целом, так формируется следующая картина изменений в сезонной цикличности. Позитивными результатами климатических изменений во II и III кварталах не удается перекрыть организационных упущений I квартала отчетного года, обусловленных, казалось бы, организационными успехами IV квартала года, принятого за базу сравнения.

Тренд-циклическая составляющая, проиллюстрированная данными графы 6 табл. 1, представлена полиномом 3-го порядка в разработке по квартальным показателям в оценке по системе наилучших функций, приведенным в графе 5 той же таблицы. Будучи построенной по приведенной шкале фактора времени, содержательно она представляет собой фрагмент долговременной годовой динамики на временном девятилетнем отрезке, охватывающем 2009-2017 гг. Цепные скоростные характеристики этого фрагмента на отрезке годовой динамики за 2017 г. по сравнению с 2016 г. показаны в графе 4, а кинетическая энергетика ее внутригодовой активности - в графе 9 табл. 3. Она получена как произведение скоростных изменений квартальных показателей (данные графы 4) на числовые значения кратности пробега годовой динамики (графа 6). Вклад внутригодовой активности в годовую динамику ВВП выражен отношением ее кинетической энергетики к базисному объему ВВП. В анализируемой ситуации в качестве базы сравнения выступает валовой внутренний продукт за 2016 г. в ценах 2009 г. в размере 158 988,8 млрд руб. По его тренд-циклической составляющей оценки вклада внутригодовой активности в годовую динамику валового внутреннего продукта показаны в графе 10 табл. 3. Их отличительная особенность отображена оценками участия вклада в годовую динамику ВВП экономической деятельности не только отчетного, но и базисного года. Данные графы 10 табл. 3 свидетельствуют о том, что посредством аддитивного агрегирования этих оценок, начиная со второго квартала базисного года, и завершая четвертым кварталом отчетного года, сформировалась накопительная вели- 
чина вклада внутригодовой активности в годовую динамику ВВП. Она представлена относительным показателем динамики, равным 1,73\% годового прироста физического объема ВВП. При этом благодаря высокой кратности пробега годовой динамики наивысший вклад внутригодовой активности припадает на первый квартал отчетного года. Тем не менее по тренд-циклической составляющей энергетика внутригодовой активности вклада в годовую динамику ВВП по всем кварталам однонаправлена и представлена позитивными оценками.

Компоненты иррегулярной составляющей взаимодействуют с годовой динамикой ВВП разнонаправленно. На одних, сравнительно непродолжительных, отрезках экономической динамики энергетика ее внутригодовой активности может способствовать позитивному движению макроэкономических процессов, на других - действовать вопреки воле и желаниям людей. В целом на среднесрочных и тем более долгосрочных траекториях экономической динамики, равнодействующие ее оценки концентрируются вблизи нулевых значений их математических ожиданий. На исследуемом отрезке экономической динамики вклад энергетики ее внутригодовой активности выразился положительной оценкой, равной $3,326 \%$. В итоге вклад кинетической энергетики внутригодовой активности в годовую динамику ВВП по трем составляющим в целом, как было показано выше, вышел на оценку 2,531\%.

По результатам синергетики исследования взаимодействия внутригодовой активности экономической деятельности и годовой динамики валового внутреннего продукта можно сформулировать следующие выводы и предложения.

Во-первых, в развитии гносеологии познания объективного мира в постньютоновский период актуальное значение приобретает исследование закономерностей взаимодействия элементов микро- и макромира. В сфере экономики в эту проблему актуально вписывается цифровая синергетика инновационного взаимодействия динамики показателей различной периодичности разработки и, в частности, внутригодовой активности экономической деятельности и годовой динамики валового внутреннего продукта.

По образу и подобию кинетической энергетики термодинамики предложена методология измерения энергетики внутригодовой активности экономической деятельности. Она представлена произведением цепных скоростных характеристик динамики показателей квартального уровня на кратность пробега годовой динамики по квартальным временным отрезкам как базисного, так и отчетного года. Путем сопоставления энергетики внутригодовой активности с базисным объемом валового внутреннего продукта достигнута оценка вклада внутригодовой активности экономической деятельности восьмиквартальной продолжительности в годовую динамику ВВП.

Во-вторых, предложена новая методология сезонной декомпозиции валового внутреннего продукта. По ее результатам определены статистически значимые составляющие его годовой динамики: динамическая составляющая сезонной цикличности, тренд-циклическая составляющая и составляющая краткосрочных колебаний. Выполнена содержательная идентификация их содержательной нагрузки и интерпретации.

Установлено, что оценки динамической составляющей сезонной цикличности, относящиеся к четвертому кварталу базисного года и первому кварталу отчетного года преимущественно сформированы под воздействием организационно-экономических факторов. В оценках динамической составляющей сезонной цикличности за второй и третий кварталы идентифицировано статистически значимое влияние природноклиматических изменений.

В составе тренд-циклической составляющей проявилась позитивная тенденция экономической динамики долговременной значимости.

Компоненты иррегулярной составляющей взаимодействуют с годовой динамикой ВВП разнонаправлено с переменными эффектами. Тем самым она наполняется экономическим содержанием составляющей крат- 
косрочных колебаний. Под ее воздействием формируются и проявляются малые и краткосрочные циклы экономической динамики.

B-третьих, автор обращает внимание на инновационные аналитические возможности, которые заключены и раскрываются с помощью тождества (4). Они могут быть реализованы при условии дополнительной разработки квартальных показателей трудовых затрат, например, количества отработанных человеко-дней или средней численности занятых работников. Потребность в разработке информационных потоков, раскрывающих взаимодействие микро- и макроуровней, ощущается в настоящее время и в цифровой экономике она непременно будет реализована. При наличии числового измерителя трудовых затрат квартальной периодичности становится возможным исчисление квартальных показателей уровня и динамики производительности труда с эффектом экономии живого и потребленного прошлого труда, то есть производительности труда в оценке по валовой добавленной стоимости на микро- и мезоуровнях и по валовому внутреннему продукту на макроуровне. Имея при этом в виду, что динамика ВВП причинно обусловлена динамикой трудовых затрат и производительности труда, с их введением в аналитическое тождество (4) открывается возможность однозначного и безальтернативного индексного моделирования годовой динамики ВВП по мультипликативным факторным переменным с применением метода изолированного влияния. Ранее в литературных источниках, посвященных многофакторному индексному моделированию, достижение такого аналитического эффекта считалось невозможным ${ }^{5}$ (Адамов, 1977. С. 61).

В-четвертых, в условиях достаточно широкого спектра объемных показателей квартальной периодичности, включая данные о факторах производства, становится возможным вести разработку квартальных показателей эффективности функционирования экономки с последующим выходом на оценку вклада их кинетической энергетики в годовую динамику.

5 Новиков М.М. (Ред.). 2005. Статистика: показатели и методы анализа: справочное пособие. Минск: «Современная школа». С. 524
С помощью тренд-циклической составляющей квартальные показатели приводятся к условиям их годовой динамики. С ее помощью становится возможным исследовать закономерности поведения годовых показателей на коротких временных отрезках: оценивать параметры скорости, ускорения, изменений в процессах ускорения (замедления); на коротких дистанциях временных периодов вести разработку спросовых моделей; исследовать воздействие подачи ресурсов факторов производства на динамику показателей скоростного режима как средства воздействия экономической активности на годовую динамику эффективности функционирования экономики и достижения целевых нормативов социально-экономического развития страны в целом (Агабекова, 2017. С. 168-171).

\section{СПИСОК ЛИТЕРАТУРЫ (REFERENCES)}

Агабекова Н.В. (Ред.). 2017. Качественные индикаторы развития Беларуси: методология оценки и анализа. Минск: БГАТУ. 288 с. [Agabekova N.V. (Ed.). 2017. Qualitative indicators of the development of Belarus: A methodology for assessing and analyzing. Minsk: BGATU. 288 p. (In Russ.)]

Адамов В.E. 1977. Факторный индексный анализ (методология и проблемы). Москва: Статистика. 200 с. [Adamov V.E. 1977. Factor index analysis (methodology and problems). Moscow: Statistika. 200 p. (In Russ.)]

Быков А.А. 2014. Технологические уклады и пространственная составляющая экономического развития. Белорусский экономический журнал. № 1. C. 114-126. [Bykau A. 2014. Technological modes and the economic developments spatial component. Belorusskiy ekonomicheskiy zhurnal. No 1. PP. 114126. (In Russ.)]

Евтянова Д.В., Тиранова М.В. 2017. Цифровая экономика как механизм эффективной экологической и экономической политики. Науковедение. T. 9. № 6. URL: https://naukovedenie.ru/ PDF/79EVN617.pdf [Evtyanova D., Tiranova M. 2017. Digital economy as a mechanism for effective environmental and economic policy. Naukovedenie. Vol. 9. No 6. (In Russ.)]

Ельсуков Е.П., Кузьмич А.И. 2018. Стратегия «Индустрия 4.0»: практика внедрения и перспективы развития систем дистанционного мониторинга на основе цифровых технологий. Бизнес. Инноващии. Экономика. Минск: Институт бизнеса БГУ. С. 206-212. [Yelsukou U., Kuzmich A. 2018. Industry 4.0 strategy: Practice of implemen- 
tation and prospects of development of distance monitoring systems based on digital technologies. Biznes. Innovatsii. Ekonomika. Minsk: Institut biznesa BGU. PP. 206-212. (In Russ.)]

Зенькова Л.П., Новиков М.М. 2019. Кратко- и среднесрочные цикль: теория формирования, методология статистического моделирования и анализа на стадии образования и использования доходов, прогнозирования. Минск: ИВЦ Минфина. 220 c. [Zen'kova L.P., Novikov M.M. 2019. Short and medium term cycles: Formation theory, methodology of statistical modeling and analysis at the stage of formation and use of income, forecasting. Minsk: IVTs Minfina. 220 p. (In Russ.)]

Капорцева О.Н. 2018. Совершенствование механизма взаимодействия макро- и микроуровней в процессе планирования инноваций и повышения конкурентоспособности промышленной продукции Республики Беларусь. Бизнес. Инноващии. Экономика. Минск: Институт бизнеса БГУ. С. 219225. [Kaportseva O. 2018. Improvement of the mechanism of macro and micro levels interaction in the process of planning innovation and increasing the competitiveness of industrial products of the republic of Belarus. Biznes. Innovatsii. Ekonomika. Minsk: Institut biznesa BGU. PP. 219-225. (In Russ.)]

Малаховская О.А., Пекарский С.Э. 2012. Исследования причинно-следственных взаимосвязей в макроэкономике: нобелевская премия по эко- номике 2011 г. Экономический журнал Высшей школь экономики. Т. 16. № 1. С. 3-30. [Malakhovskaya O.A., Pekarski S.E. 2012. Studies of Cause-Effect Relationships in Macroeconomics: Nobel Prize in Economics in 2011. Ekonomicheskiy zhumal Vysshey shkoly ekonomiki. Vol. 16. No 1. (In Russ.)]

Пригожин И., Стенгерс И. 1986. Порядок из хаоса. Новый диалог человека с природой. Москва: Прогресс. 432 с. [Prigogine I., Stengers I. 1986. Order Out of Chaos. Man's New Dialogue with Nature. Moscow: Progress. 432 p. (In Russ.)]

Рудый К.В. (Ред.). 2017. «Потому что так решили мы»: поведенческая экономика Беларуси и ее раскодирование. Минск: Звязда. 368 с. [Rudy K. 2017. «Because we decided so»: the behavioral economy of Belarus and its decoding. Minsk: Zvyazda. 368 p. (In Russ.)]

Румянцева О.И. 2014. Денежно-кредитная политика в Республике Беларусь: теория, методология, стратегия. Минск: Мисанта. 251 с. [Rumiantseva O. 2014. Monetary policy in the Republic of Belarus: theory, methodology, strategy. Minsk: Misanta. 251 p. (In Russ.)]

Bernanke B.S., Woodford M. (Eds.). 2005. The inflation-targeting debate. University of Chicago Press. PP. 283-310.

Hansen L.P., Sardgent T.J. 2008. Robustness. Princeton: Princeton University Press.

In citation: Belorusskiy Economicheskiy zhurnal. 2020. No 2. P. 118-131.

Belarusian Economic Journal. 2020. No 2. PP. 118-131.

\title{
DIGITAL SYNERGETICS OF INTERACTION BETWEEN WITHIN-YEAR ECONOMIC ACTIVITY AND ANNUAL GDP DYNAMICS
}

\author{
Michail Novikov ${ }^{1}$
}

Authors affiliation: ${ }^{1}$ Belarus State Economic University (Minsk, Belarus).

Corresponding author: Michail Novikov (mm_novikov@rambler.ru).

ABSTRACT. According to the results of the decomposition of the observed levels of quarterly GDP indicators statistically relevant components of its dynamics are identified: the dynamic component of seasonal cyclic nature, the trend-cyclic component, and that of short-term fluctuations. A methodology is suggested for studying the impact of within-year economic activity energy on the dynamics of annual GDP indicators.

The research analytics was tested on the actual materials of annual and quarterly indicators of the Gross Domestic Product of the Republic of Belarus over the period of 2009-2017.

KEYWORDS: treduced time factor scale, gross domestic product, quarterly and annual periodicity, kinetic energy, within-year activity, annual dynamics.

JEL-code: C22, C43, C82, E32, H12.

DOI: $10.46782 / 1818-4510-2020-2-118-131$

Received 12.02.2020 